\title{
High accumulation of $\gamma$-linolenic acid and Stearidonic acid in transgenic Perilla (Perilla frutescens var. frutescens) seeds
}

Kyeong-Ryeol Lee ${ }^{1 \dagger}$, Kyung-Hwan Kim ${ }^{1 * \dagger}$, Jung Bong Kim² ${ }^{2}$ Seung-Bum Hong ${ }^{3}$, Inhwa Jeon ${ }^{1}$, Hyun Uk Kim ${ }^{4}$, Myung Hee Lee ${ }^{5}$ and Jae Kwang Kim ${ }^{6}$

\begin{abstract}
Background: Polyunsaturated fatty acids such as linoleic acid (LA) and a-linolenic acid (ALA) are abundant in vegetable oils and are important for human health. In the body, LA and ALA are respectively converted to the omega- 6 fatty acid $\gamma$-linolenic acid (GLA) and the omega-3 fatty acid stearidonic acid (SDA) by $\Delta 6$ desaturase (D6DES). Currently, dietary GLA and SDA are mainly obtained from marine organisms, but given their benefits to human health, many studies have aimed to enhance their accumulation in transgenic crops. Perilla frutescens (perilla) accumulates more ALA in its seed oil compared to other oilseed crops, making it a good candidate for the production of fatty acids via the fatty acid desaturase D6DES.

Results: In this study, we cloned the D6DES gene from Phytophthora citrophthora and confirmed its function in budding yeast. We then transformed the functional D6DES gene under the control of the seed-specific vicilin promoter into the perilla cultivar Yeobsil. The resulting transgenic perilla seeds accumulated significant levels of GLA and SDA, as well as putative C18:2 $\Delta^{6,9}$ at minor levels. Developing seeds and leaves also accumulated GLA and SDA, although PCD6DES expression and GLA and SDA levels were much lower in leaves compared to developing seeds. GLA and SDA accumulated in both polar lipids and neutral lipids in mature perilla seeds expressing PCD6DES, especially in neutral lipids. Although the seed weight in PCD6DES perilla was 87-96\% that of wild type, the total oil content per seed weight was similar between lines. The PCD6DES perilla plants contained very high content (over 45\%) of both GLA and SDA in seed oil.
\end{abstract}

Conclusions: Thus, PCD6DES perilla plants may represent a feasible alternative to traditional marine sources for the production of omega-3 oil capsules and to evening primrose seed oil for GLA as health food. In addition, these plants can be used to create other transgenic lines harboring additional genes to produce other desirable fish-oil like oils.

Keywords: Delta 6 desaturase, $y$-Linolenic acid, Stearidonic acid, Perilla, Phytophthora citrophthora

\section{Background}

Along with high proportions of other fatty acids from plants, polyunsaturated fatty acids (PUFAs) such as cis-9,12-octadecadienoic acid (linoleic acid; LA) and cis-9,12,15-octadecatrienoic acid ( $\alpha$-linolenic acid; ALA) are essential to human health. These PUFAs are used to produce cis-6,9,12-octadecatrienoic acid ( $\gamma$-linolenic acid; GLA) and

* Correspondence: biopiakim@korea.kr

${ }^{\dagger}$ Kyeong-Ryeol Lee and Kyung-Hwan Kim contributed equally to this work. ${ }^{1}$ Department of Agricultural Biotechnology, National Institute of Agricultural Science, RDA, Jeonju 54874, Jeollabukdo, Republic of Korea

Full list of author information is available at the end of the article cis-6,9,12,15-octadecatrienoic acid (stearidonic acid; SDA), which are health-promoting molecules as well as serving as precursors for the very long chain polyunsaturated fatty acids (VLCPUFAs) found in algae, fungi and vertebrates, including fish and human. GLA is an omega- 6 fatty acid that acts as an anti-inflammatory agent and relieves skin problems, such as atopy $[1,2]$. SDA is an omega-3 fatty acid that serves a precursor for other omega-3 fatty acids such as cis-5,8,11,14,17-eicosapentaenoic acid (EPA) and cis-4,7,10,13,16,19-docosahexaenoic acid (DHA), a representative $\omega-3$ VLCPUFAs. In humans, dietary SDA is more

(c) The Author(s). 2019 Open Access This article is distributed under the terms of the Creative Commons Attribution 4.0 International License (http://creativecommons.org/licenses/by/4.0/), which permits unrestricted use, distribution, and reproduction in any medium, provided you give appropriate credit to the original author(s) and the source, provide a link to the Creative Commons license, and indicate if changes were made. The Creative Commons Public Domain Dedication waiver (http://creativecommons.org/publicdomain/zero/1.0/) applies to the data made available in this article, unless otherwise stated. 
efficiently converted to EPA compared to ALA [3], and SDA therefore provides similar health benefits to humans as $\omega-3$ VLCPUFAs [4]. In addition, SDA has been characterized as a potent inhibitor of cancer cell growth and an effective molecule against skin inflammation and atopic dermatitis that also prevents hypertriglyceridemia [5].

As humans can synthesize DHA from either ALA or SDA, it may be beneficial for humans to take in high levels of ALA and/or SDA through their diet. GLA and/or SDA are present in the seed oils of several plant species, such as evening primrose (Oenothera biennis) [6], blackcurrant (Ribes nigrum) [7], Primula spp. [8], Echium spp. [9], hemp (Cannabis sativa) [10] and Boraginaceae plants [11], including borage (Borago officinalis). However, these wild plants do not produce large amounts of oil, and they produce only low levels of GLA and SDA. Consequentially, GLA- and SDA-containing health foods are rather expensive.

GLA and SDA are converted from LA and ALA, respectively, through desaturation at the sixth carbon, a process catalyzed by $\Delta 6$ desaturase (D6DES). Fungal D6DES can also convert oleic acid to $\mathrm{C} 18: 2 \Delta^{6,9}[12,13]$, and ALA-specific D6DES from Primula spp. synthesizes only SDA $[14,15]$. The D6DES gene, which was first identified in a cyanobacterium [16], encodes a divergent form of the sphingolipid $\Delta 8$-desaturase [17]. Subsequently, $D 6 D E S$ genes have been identified in bacteria, algae, fungi, mosses, vertebrates and several plant species [18]. Fatty acid desaturases involved in the synthesis of VLCPUFA, including D6DES, are "front-end" desaturases that contain a cytochrome $b 5$ (cyb5) domain at their N-termini, which is essential for fatty acid desaturation [19-21].

Perilla (Perilla frutescens var. frutescens) is an annual herbaceous plant belonging to the mint family, Lamiaceae. Perilla has been widely cultivated as an oilseed crop and leaf vegetable in East Asia. Perilla seed oil is used as both an edible and an industrial crop in products such as paint, varnish and ink [22]. Perilla seeds comprise 35-45\% oil and accumulate one of the highest proportions of ALA (54-64\%) in the plant kingdom [22]. The mechanism underlying the production of high levels of ALA is of interest, and thus, transcriptome analysis has been performed to identify perilla genes involved in ALA bisoynthesis and accumulation [23]. PUFAs represent approximately $80 \%$ of the total fatty acid composition in perilla seeds, which could confer health benefits for humans [24]. We therefore hypothesized that if perilla were transformed with the D6DES gene, it would produce high amounts of GLA and/or SDA and serve as a feasible resource for large-scale GLA and/or SDA production. Furthermore, the seeds from these transgenic crops could potentially be used for effective, large-scale production of EPA or DHA.

In this study, we confirmed that D6DES from the fungus Phytophthora citrophthora synthesizes GLA and SDA from LA and ALA, respectively, in budding yeast. We further revealed that transgenic perilla seeds expressing PcD6DES produced very high levels of GLA and SDA, with each accounting for over $20 \%$ of the seed oil content. Our results indicate that PCD6DES and perilla are an effective gene and host combination that could be utilized to efficiently produce GLA and SDA.

\section{Methods \\ Plant material}

Perilla frutescens var. frutescens cv. Yeobsil was grown in a greenhouse and the seeds were harvested for transformation. The seeds were surface sterilized in $70 \%(v / \mathrm{v})$ ethanol for $1 \mathrm{~min}$, followed by 4 -fold diluted commercial bleach for $20 \mathrm{~min}$, washed three times with sterile distilled water and immersed in sterile distilled water for 2 $\mathrm{h}$ at room temperature. After brief drying on sterile filter paper, the seeds were placed on Murashige and Skoog (MS) basal medium [25] supplemented with $30 \mathrm{~g} / \mathrm{L} \mathrm{su}$ crose and $0.4 \%(w / v)$ Phytagel (Sigma, USA) with the $\mathrm{pH}$ adjusted to 5.8 before autoclaving. Surface sterilized seeds were germinated in a culture room at $28{ }^{\circ} \mathrm{C}$ under a 16 h:8 h (light: dark) photoperiod.

\section{Gene cloning}

The D6DES gene was cloned from $P$. citrophthora (KACC 40188), which was obtained from the National Agrobiodiversity Center, National Institute of Agricultural Science, RDA, Republic of Korea. Total RNA was extracted from P. citrophthora for D6DES gene cloning. First-strand cDNA was synthesized from total RNA using a PrimeScript $^{\text {TM }} 1$ st strand cDNA Synthesis Kit (Takara, Japan) following the manufacturer's protocol. Degenerate PCR and $5{ }^{\prime}-/ 3^{\prime}$-RACE PCR were used for cloning. Primer sequences for degenerate PCR were designed based on consensus sequences of D6DES from the fungus Mucor circinelloides and Rhizopus stolonifera var. stolonifer. Degenerate PCR was performed at $94^{\circ} \mathrm{C}$ for $5 \mathrm{~min}$, followed by 30 cycles of $94{ }^{\circ} \mathrm{C}$ for $20 \mathrm{~s}, 54{ }^{\circ} \mathrm{C}$ for $30 \mathrm{~s}$ and $72{ }^{\circ} \mathrm{C}$ for $1 \mathrm{~min}$, with an additional extension at $72^{\circ} \mathrm{C}$ for $5 \mathrm{~min}$. PCR amplification was performed with the degenerate primers using Ex Taq polymerase (Takara, Japan). RACE PCR was performed using a SMART RACE cDNA Amplification Kit (Clontech, USA) following the manufacturer's protocol. The D6DES gene from P. citrophthora (PcD6DES) was registered in GenBank NCBI under Accession No. DQ836059. Primers used in these procedures are listed in Additional file 1: Table S1.

\section{Vector construction}

To confirm the function of PcD6DES in budding yeast (Saccharomyces cerevisiae), the PcD6DES gene was subcloned in between the HindIII and BamHI sites of the pYES2/CT vector (Invitrogen, USA) harboring the galactose-inducible GAL1 promoter and URA3 gene. The complete vector was 
named pYES2-PCD6DES. The process used to transform and express the PCD6DES gene in perilla was as follows: the $\mathrm{pVi}$ cOCS vector containing the seed-specific vicilin promoter and octopine synthase III (OCSIII) terminator was digested with BamHI and HindIII, and the ORF of PcD6DES was inserted between the vicilin promoter and OCSIII terminator. The vicilin promoter-PcD6DES-OCSIII terminator cassette was inserted into the multiple cloning site of pCAMBIA3300. The complete vector was named pCAMBIA-PCD6DES. The destination vectors used in this study are shown in Additional file 2: Figure S1.

\section{Phylogenetic and transmembrane domain analysis}

The sequences of D6DES genes registered in GenBank were collected by carrying out BLASTN with the PcD6DES gene sequence as a query. The phylogenetic relationship of these D6DES genes was analyzed using DNASTAR MegAlign (Ver. 7.2.1) via the ClustalW method. A phylogenetic tree was constructed from the alignment data using TreeView (Ver. 1.6.6). The transmembrane domain was predicted with TOPCONS (http://topcons.cbr.su.se/).

\section{Yeast transformation and culture}

Saccharomyces cerevisiae INVSc1 (Invitrogen, USA) was used for the expression of PCD6DES and subsequent production of GLA and SDA. Yeast transformation was carried out in accordance with the manufacturer's protocol. Yeast culture and induction of PcD6DES were performed as follows: Yeast cells containing pYES2-PcD6DES were cultured in uracil-deficient medium containing with $2 \%$ raffinose and $1 \%$ Tergitol NP- 40 at $30{ }^{\circ} \mathrm{C}$. At O.D $\mathrm{D}_{600}=$ $0.5-0.6,0.5 \mathrm{mM}$ of the substrates LA and ALA with $2 \%$ galactose as an inducer were added to the culture, followed incubation for 3 days at $20^{\circ} \mathrm{C}$.

\section{Perilla transformation}

Perilla transformation was performed as described by Kim et al. [26] with slight modifications. Agrobacterium tumefaciens strain EHA105 harboring pCAMBIA-PcD6DES was inoculated in Luria Bertani broth containing $50 \mathrm{mg} / \mathrm{L}$ kanamycin and $50 \mathrm{mg} / \mathrm{L}$ rifampicin and cultured at $28^{\circ} \mathrm{C}$ overnight. The cells were harvested and resuspended in liquid MS basal medium. Hypocotyl pieces 0.5 to $1 \mathrm{~cm}$ in length were excised from in vitro-grown seedlings and inoculated with Agrobacterium solution for $1 \mathrm{~h}$. After brief blotting with sterile filter paper, the explants were transferred to MS basal medium supplemented with $30 \mathrm{~g} / \mathrm{L}$ sucrose and $0.4 \%$ Phytagel and co-cultured for 2 days at $26^{\circ} \mathrm{C}$ in the dark. After co-culture, the explants were transferred to fresh MS medium supplemented with $30 \mathrm{~g} / \mathrm{L}$ sucrose, $3.0 \mathrm{mg} / \mathrm{L}$ benzyladenine, 0.01 $\mathrm{mg} / \mathrm{L}$ naphthaleneacetic acid, $2 \mathrm{mg} / \mathrm{L}$ phosphinothricin, 400 $\mathrm{mg} / \mathrm{L}$ carbenicillin and $0.4 \%$ Phytagel. The explants were subcultured every two weeks for 8 weeks. The shoots that regenerated on the explants were excised and transferred to fresh selective MS basal medium for shoot elongation. The elongated shoots were transferred to half-strength MS basal medium for rooting. When whole plants had formed, they were acclimated on commercial soil in an airtight container for 1 week and transferred to the greenhouse.

\section{Fatty acid composition analysis and the determination of seed oil content}

Fatty acid extraction and FAME preparation in yeast cells were followed slightly modified version of method by Kim et al. [27]. Yeast cells were centrifuged, resuspended in 1 volume of distilled water to remove residual fatty acids (LA and ALA), harvested and lyophilized for $48 \mathrm{~h}$. Lipids of freeze-dried yeast cells with $0.5 \mathrm{mg}$ pentadecanoic acid were extracted with $5 \mathrm{~mL}$ extraction solution (chloroform: methanol $=2: 1, v / v$ ) via sonication at room temperature. Five milliliters of $0.58 \% \mathrm{NaCl}$ solution was added to the mixture and centrifuged at 2000 $\mathrm{rpm}$ for $10 \mathrm{~min}$. The supernatant was discarded and the lower phase was dried under a flow of nitrogen. Toluene $(0.5 \mathrm{~mL})$ and $0.5 \mathrm{~N} \mathrm{NaOH}$ in methanol were added to the dried samples, and the transmethylation mixture was reacted in boiling water for 3 min. After cooling, $2 \mathrm{~N} \mathrm{BF}_{3}$ in methanol was added to the mixture, which was reacted once more for $5 \mathrm{~min}$. Ten milliliters of distilled water and $10 \mathrm{~mL}$ petroleum ether were added to the sample, followed by centrifugation. The supernatant containing fatty acid methyl esters (FAMEs) was collected for gas chromatography (GC) analysis performed on a HP 5890 (Agilent, USA) with flame ionization detector (FID) and $25 \mathrm{~m} \times 0.2 \mathrm{~mm}$ (inner diameter) HP 20 $\mathrm{M}$ from $180^{\circ} \mathrm{C}$ to $200^{\circ} \mathrm{C}$ at $1{ }^{\circ} \mathrm{C} / \mathrm{min}$.

Perilla seeds were weighed and crushed with a metal stick in a glass tube. A mixture of LA (Sigma, St. Louis, MO, USA), GLA (Matreya, PA, USA), ALA (Sigma, St. Louis, MO, USA) and SDA (Santa Cruz Biotechnology, CA, USA) was used as an external standard. Seed samples and the external standard were transmethylated at $85^{\circ} \mathrm{C}$ for $90 \mathrm{~min}$ in $0.3 \mathrm{~mL}$ of toluene and $1 \mathrm{~mL}$ of $5 \% \mathrm{H}_{2} \mathrm{SO}_{4}(\mathrm{v} / \mathrm{v})$ in methanol. Pentadecanoic acid $(100 \mu \mathrm{g})$ was added to each sample as an internal standard. After transmethylation, $1.5 \mathrm{~mL}$ of $0.9 \%$ $\mathrm{NaCl}$ solution was added to the sample and the FAMEs were transferred to a new tube after extracting the sample three times with $1.5 \mathrm{~mL}$ of $\mathrm{n}$-hexane. The FAMEs were analyzed by GC-2010 plus (Shimadzu, Japan) GC with FID and a 30 $\mathrm{m} \times 0.25 \mathrm{~mm}$ (inner diameter) HP-FFAP column (Agilent, USA) while increasing the oven temperature from $190^{\circ} \mathrm{C}$ to $230^{\circ} \mathrm{C}$ at $3{ }^{\circ} \mathrm{C} / \mathrm{min}$. Nitrogen was used as the carrier gas in both cases for fatty acid analysis.

Seed oil contents were determined based on the results by fatty acid analyses. The formula for seed oil content is as follows. Seed oil content $=($ Total peak area of all seed fatty acids except internal standard)*(mass of internal standard)/ (peak area of internal standard). 


\section{GC-TOF MS analysis}

Each FAME sample $(1 \mu \mathrm{L})$ was injected into the Agilent 7890A GC with an Agilent 7683B autosampler (Agilent, Atlanta, GA, USA) with a split ratio of 25 and separated in a $30 \mathrm{~m} \times 0.25 \mathrm{~mm}$ I.D. fused-silica capillary column coated with $0.25 \mu \mathrm{m}$ CP-SIL 8 CB Low Bleed (Varian Inc., Palo Alto, CA, USA). The injector temperature was $230{ }^{\circ} \mathrm{C}$. The helium gas flow rate through the column was $1.0 \mathrm{~mL} / \mathrm{min}$. The temperature program was as follows: starting temperature $80^{\circ} \mathrm{C}$, maintained for $2 \mathrm{~min}$, followed by an increase to $320^{\circ} \mathrm{C}$ at $15^{\circ} \mathrm{C} / \mathrm{min}$ and a 10 min hold at $320^{\circ} \mathrm{C}$. The transfer line and ion-source temperatures were 250 and $200^{\circ} \mathrm{C}$, respectively. The scanned mass range was $85-600 \mathrm{~m} / z$, and the detector voltage was set at $1700 \mathrm{~V}$.

\section{Thin layer chromatography (TLC)}

Lipid extraction and TLC were performed based on Kim et al. [28]. Briefly, lipids were extracted with extraction solution (chloroform: methanol = 2:1, v/v) from ground perilla seeds and spotted onto silica gel G60 plates (Merck Millipore, USA). Lipid samples were separated using developing solvent (hexane: diethylether: acetic acid = 70:30:1, v/v/v) in a TLC developing tank for $50 \mathrm{~min}$ at room temperature. The silica gel plate was removed from the TLC developing tank and sprayed with $0.1 \%$ primuline (Sigma, St. Louis, MO, USA) in 80\% acetone. Lipid spots were visualized on an ultraviolet transilluminator. A large spot at the top (TAG), two small spots in the middle (diacylglycerol) and two small spots around the baseline (polar lipids) were scraped off the TLC plate with a scalpel and subjected to fatty acid analysis.

\section{RT-PCR and quantitative RT-PCR}

Total RNAs of yeast cells and perilla tissues were extracted with RNeasy Mini kit and RNeasy Plant Mini kit (Qiagen, USA), respectively. First-strand cDNA was synthesized using RNA to cDNA EcoDry Premix (Clontech, USA) following the manufacturer's protocol. RT-PCR was carried out using ExTaq DNA polymerase (Takara, Japan) and $1 \mu \mathrm{g}$ first-strand cDNA from yeast RNA as a template. The PCR conditions were as follows: $94{ }^{\circ} \mathrm{C}$ for $3 \mathrm{~min}, 30$ cycles of $94^{\circ} \mathrm{C}$ for $20 \mathrm{~s}, 55^{\circ} \mathrm{C}$ for $20 \mathrm{~s}$ and $72^{\circ} \mathrm{C}$ for $80 \mathrm{~s}$, and additional extension at $72{ }^{\circ} \mathrm{C}$ for $5 \mathrm{~min}$.

Quantitative RT-PCR was carried out with SYBR premix Ex Taq II (Tli RNaseH plus; Takara, Japan), and first-strand cDNA diluted 20-fold was used as template for PCR on a StepOnePlus Real-Time PCR System (Applied Biosystems, USA). The PCR conditions were as follows: $94{ }^{\circ} \mathrm{C}$ for $30 \mathrm{~s}$, 40 cycles of $94{ }^{\circ} \mathrm{C}$ for $5 \mathrm{~s}, 55^{\circ} \mathrm{C}$ for $20 \mathrm{~s}$ and $72{ }^{\circ} \mathrm{C}$ for $20 \mathrm{~s}$, and an additional cycle of $94^{\circ} \mathrm{C}$ for $15 \mathrm{~s}, 55^{\circ} \mathrm{C}$ for $1 \mathrm{~min}$, and finally, after increasing the temperature at $0.5^{\circ} \mathrm{C} / \mathrm{min}, 94^{\circ} \mathrm{C}$ for $15 \mathrm{~s}$. Quantitation was performed using StepOne software ver. 2.3 (Applied Biosystems, USA), employing perilla $\beta$-actin as a reference gene. Primers were designed with the GenScript website for real-time PCR primer design to generate approximately $200 \mathrm{bp}$ amplicons with a $55^{\circ} \mathrm{C}$ melting temperature (https://www.genscript.com/ssl-bin/app/primer). Primers for qRT-PCR are listed in Additional file 1: Table S1.

\section{Results \\ PCD6DES gene cloning and sequence analysis}

We began by cloning the full-length PCD6DES mRNA, which was 1529 bp with a 1371 bp sequence encoding 456 aa. Residues 11 to 81 were predicted to form a cyb5 domain, which is characteristic of front-end desaturases (Fig. 1) [20]. In addition to the cyb5 domain, fatty acid desaturases contain the heme-binding motif HPGG- $\mathrm{X}_{8}-\mathrm{G}-\mathrm{X}_{6}-\mathrm{F}-\mathrm{X}_{3-6}-\mathrm{H}$ known as HPGG [19]. PCD6DES encodes a protein with an HPGG motif at 42-45 aa, with the sequence HPGG- $\mathrm{X}_{7}-\mathrm{G}-\mathrm{X}_{6}-\mathrm{F}-\mathrm{X}_{3}-\mathrm{H}$, in the cyb5 domain. In addition, PcD6DES has three histidine boxes (His boxes): HDVLHH, HNFHH and QIEHH. His boxes are the most important characteristics of fatty acid desaturases, as they determine their desaturase function $[29,30]$. The His boxes of common fatty acid desaturases have the sequences HXXXH, HXXHH and $\mathrm{HXXHH}$. Importantly, the third His box of the front end desaturase has the sequence QXXHH, and it appears that the $\mathrm{Q}$ residue mediates desaturase function [30]. The sequences of the His boxes of PcD6DES (HDVLHH, HNFHH and QIEHH) are consistent with the conserved His box motifs HXXXH, HXXHH and QXXHH of D6DES (Fig. 1) [30]. Finally, most membrane-bound fatty acid desaturases have four to six transmembrane domains (TMs) [31-33], and PcD6DES was predicted to have six TM domains (Fig. 1, Additional file 2: Figure S2). TM1 to TM6 were predicted to be located sequentially at 128-148 aa, 153-173 aa, 191-211 aa, 267-287 aa, 305-325 aa and 328-348 aa (Fig. 1, Additional file 2: Figure S2).The TMs patterns of of PcD6DES, evening primrose D6DES, perilla FAD2 are very similar to among them (Additional file 2: Figure S2).

\section{Phylogenetic analysis}

We performed phylogenetic analysis of D6DES peptide sequences from 25 species belonging to the Protista, Fungi, Plantae and Animalia kingdoms (Fig. 2). The D6DES sequences formed groups within each kingdom. The identity between PcD6DES (DQ3605) and PinD6DES (JF910287), which were the first and second reported D6DES in the Phytophthora genus, respectively, was 90.8\%. However, the identity between PCD6DES and other fungal D6DES proteins was at most $64.1 \%$. Furthermore, for the Fungi and Protista, the identities among deduced amino acids of D6DES genes were low (38.2 and 55.2\%, respectively).

\section{Functional analysis in Saccharomyces cerevisiae}

We compared the fatty acid composition between the control yeast strain and pYES2-PcD6DES yeast to investigate the 


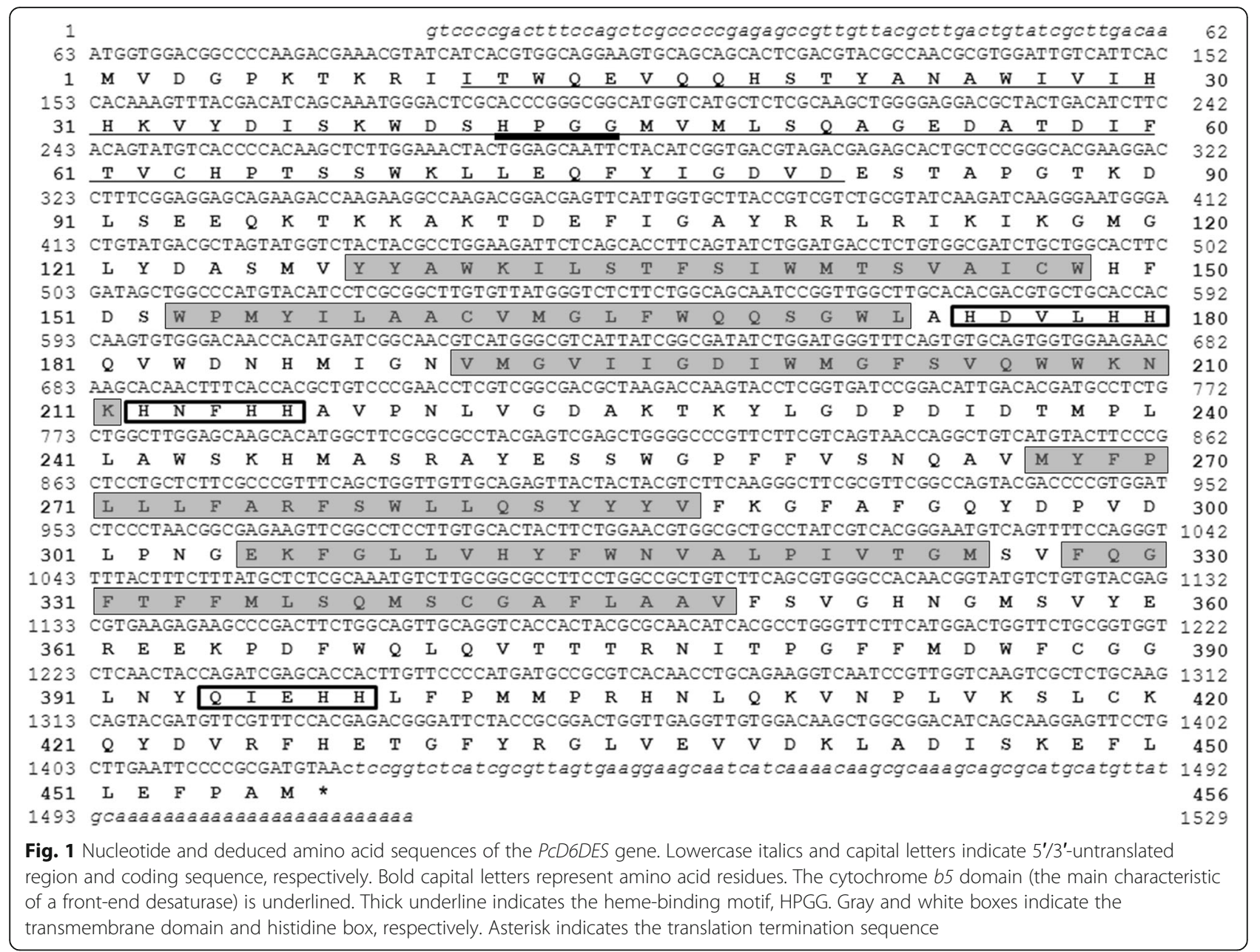

production of SDA and GLA and confirm PcD6DES function. Above all, the expression of PcD6DES in transformed yeast cells was confirmed using RT-PCR (Additional file 2: Figure S3). Yeast harboring the pYES2 empty vector, which served as a control, only produced hexadecanoic acid (palmitic acid; C16:0), cis-9-hexadecanoic acid (palmitoleic acid; C16:1 $\Delta^{9}$ ), octadecanoic acid (stearic acid; C18:0) and cis-9-octadecenoic acid (oleic acid; $\mathrm{C} 18: 1 \Delta^{9}$ ). Furthermore, when provided with LA, this control yeast strain did not produce any other fatty acids. However, pYES2-PCD6DES yeast supplemented with LA produced GLA. In addition, pYES2-PcD6DES yeast supplied with LA and ALA synthesized SDA as well as GLA (Table 1). These results demonstrate that the PcD6DES gene encodes a protein that can convert LA and ALA to GLA and SDA, respectively, in yeast.

We also analyzed the conversion rate of products by PcD6DES. In the case of pYES2-PcD6DES supplied with LA, the conversion rate of GLA was $11.6 /(25.1+11.6)=$ $31.6 \%$, putative $C 16: 2 \Delta^{6,9}$ was $3.1 /(15.8+3.1)=16.4 \%$ and the total conversion rate was $26.4 \%$ (Table 1 ). In the case of pYES2-PcD6DES supplied with both LA and ALA, the conversion rate of GLA was 5.3/(21.5 + 5.3) $=19.8 \%$, SDA was $8.8 /(25.1+8.8)=26.0 \%$, putative $\mathrm{C} 16: 2 \Delta^{6,9}$ was $0.6 /$ $(6.8+0.6)=8.1 \%$ and the total conversion rate was $21.6 \%$ (Table 1). The ratios of saturated fatty acids to unsaturated fatty acids were not significantly different in yeast cultures supplemented with LA and/or ALA and without LA and/ or ALA (Table 1). A putative cis-6,9-octadecadienoic acid $\left(\mathrm{C} 16: 2 \Delta^{6,9}\right)$ peak was detected in the samples and putative C18:2 $\Delta^{6,9}$ was also detected, but at a much lower proportion than $C 16: 2 \Delta^{6,9}$ (Table 1).

\section{Fatty acid analysis and segregation ratio of transgenic perilla}

Five $\mathrm{T}_{0}$ PcD6DES transgenic perilla plants (PD6Ds) were obtained by Agrobacterium-mediated transformation. The transformants were confirmed by PCR of the PCD6DES gene and phosphinothricin acetyltransferase gene, which confers resistance to the herbicide Basta (Bayer Crop Science, Republic of Korea). We analyzed the fatty acid compositions of the $T_{2}$ PD6D seeds from two $T_{1}$ PD6Ds of each line (Table 2). Three new peaks, which were absent in 


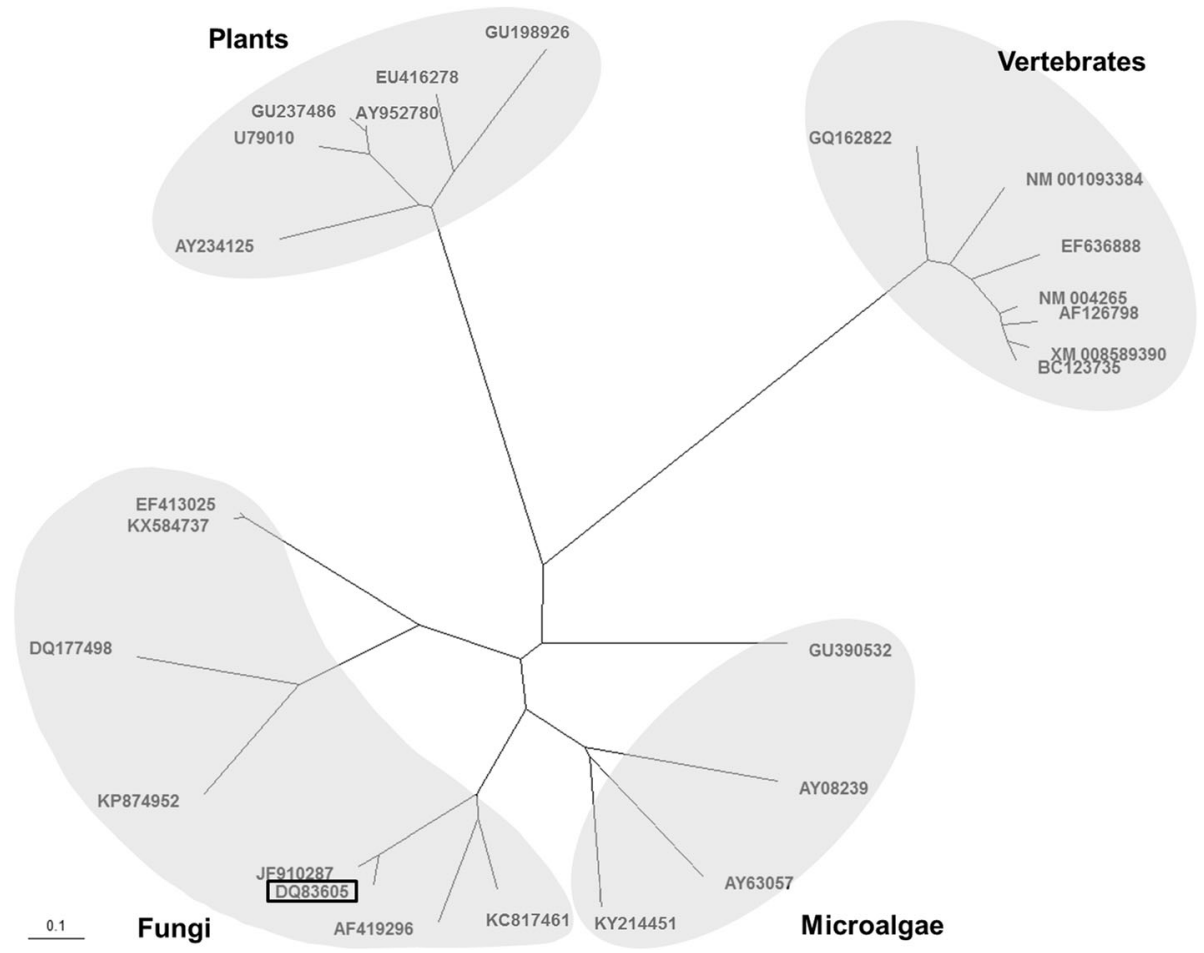

Fig. 2 Phylogenetic analysis of the deduced amino acid sequences of D6DES genes from various organisms. D6DES from microalgae (Protista), fungi (Fungi), plants (Plantae) and vertebrates (Animalia) are separately grouped by kingdom. Letters and numbers represent GenBank accession numbers. The origin of each D6DES is as follows: AF126798, Mus musculus; AF419296, Pythium irregulare; AY08239, Phaeodactylum tricornutum; AY234125, Primula farinosa; AY63057, Glossomastix chrysoplasta; AY952780, Echium plantagineum; BC123735, Bos taurus; DQ177498, Cunninghamella echinulata; DQ83605, Phytophthora citrophthora; EF413025, Mortierella alpina; EF636888, Gallus gallus; EU416278, Oenothera biennis; GQ162822, Sparus aurata; GU198926, Ribes nigrum; GU237486, Echium amoenum; GU390532, Parietochloris incisa; JF910287, Phytophthora infestans; KC817461, Pythium aphanidermatum; KP874952, Umbelopsis isabellina; KX584737, Mortierella alpina; KY214451, Nannochloropsis oceanica; NM_001093384, Xenopus laevis; NM_004265, Homo sapiens; U79010, Borago officinalis; XM_008589390, Galeopterus variegatus. Open box indicates PCD6DES. Sequences were aligned using DNASTAR MegAlign (Ver. 8.1.4) with the ClustalW method. The phylogenetic tree was generated using TreeView (Ver. 1.6.6) with the aligned data. Scale bar indicates 0.1 amino acid substitution per site

Yeobsil, appeared in the chromatogram from PD6D seeds (Fig. 3). The retention times of two peaks of them, located earlier and later than that of ALA, are the same as that of GLA and SDA in the external standard, respectively (Fig. 3). The remaining new peak that appeared in front of the LA peak was putative C18:2 $\Delta^{6,9}$, as expected (Fig. 3), as this compound is found in some fungi (Table 2) [12, 13]. In transgenic PD6D plants, the proportions of GLA, SDA and putative C18:2 $\Delta^{6,9}$ increased while the proportions of oleic acid, LA and ALA decreased. In particular, the ALA content was significantly reduced in PD6D, likely due to GLA and SDA synthesis expending their respective substrates LA and ALA. Oleic acid content decreased in PD6D compared with Yeobsil (Table 2), likely as a consequence of increasing PUFA content. There were two types of $\mathrm{T}_{1}$ PD6Ds whose $\mathrm{T}_{2}$ seeds contained over $46 \%$ or 28 $35 \%$ GLA and SDA content in seed oil, respectively. We hypothesized that the variance resulted from the difference in $P c D 6 D E S$ gene expression levels between the homozygote and hemizygote. To measure the segregation ratio, we treated $40-50 \mathrm{~T}_{1}$ seedlings with $0.3 \%$ Basta and investigated the segregation ratios of the progenies of four $\mathrm{T}_{0}$ PD6D lines. All four $\mathrm{T}_{1}$ perilla lines segregated at a ratio of 3:1 (Additional file 1: Table S2).

\section{Confirmation of the putative $C 18: 2 \Delta^{6,9}$ peak}

To confirm the identity of the putative $C 18: 2 \Delta^{6,9}$, we analyzed this compound from PcD6DES perilla seed oil using Pegasus HT GC-TOF MS (LECO, USA). LA and $C 18: 2 \triangle^{6,9}$ are isomers whose double bond positions differ from each other. In the GC-TOF MS results, two slightly different peaks and mass spectra were observed (Fig. 4). In addition, these peaks were identified by matching their mass spectra from the NIST11 and Wiley9 mass libraries. Finally, the peak between the oleic acid and LA peaks was possibly C18:2 $\Delta^{6,9}$. 
Table 1 Fatty acid composition of pYES2-PCD6DES yeast cultured in medium containing fatty acid substrates. Trace indicates below 0.1 mole\%. Data represent mole\% of fatty acid methyl esters. Experiments were carried out in triplicate, and the mean values are displayed

\begin{tabular}{|c|c|c|c|c|}
\hline \multirow[t]{2}{*}{ Fatty acid } & \multicolumn{2}{|l|}{ pYES2 } & \multicolumn{2}{|c|}{ pYES2-PCD6DES } \\
\hline & - & $+\mathrm{LA}$ & $+\mathrm{LA}$ & $+L A$ and $A L A$ \\
\hline $\mathrm{C} 16: 0$ & 17.4 & 18.1 & 20.7 & 15.9 \\
\hline $\mathrm{C} 16: 1 \Delta^{9}$ & 41.2 & 15.2 & 15.8 & 6.8 \\
\hline$C 16: 2 \Delta^{6,9}$ & - & - & 3.1 & 0.6 \\
\hline C18:0 & 7.2 & 7.1 & 7.9 & 7.7 \\
\hline $\mathrm{C} 18: 1 \Delta^{9}$ & 34.2 & 13.8 & 15.8 & 8.3 \\
\hline$C 18: 2 \Delta^{6,9}$ & - & - & trace & trace \\
\hline LA & - & 45.8 & 25.1 & 21.5 \\
\hline GLA & - & - & 11.6 & 5.3 \\
\hline ALA & - & - & - & 25.1 \\
\hline SDA & - & - & - & 8.8 \\
\hline Conversion rate (\%) & - & - & 26.4 & 21.6 \\
\hline Saturated FA: unsaturated FA & $1: 3.07$ & $1: 2.97$ & $1: 2.50$ & $1: 3.24$ \\
\hline
\end{tabular}

\section{PCD6DES expression in leaves and developing seeds of transgenic PCD6DES perilla}

We performed quantitative RT-PCR (qRT-PCR) to measure the expression levels of $P c D 6 D E S$ and other fatty acid desaturase genes in leaves and developing seeds from Yeobsil and PD6D (Fig. 5). In DS3 of Yeobsil or PD6D 41-1, the expression of fatty acid desaturase 2 gene from $P$. frutescens (PfFAD2) and PfFAD3 was relatively high compared to that of PfFAD7-1 and PfFAD7-2. PCD6DES was highly expressed during DS3 of PD6D 4-1-1; however, it was not expressed in Yeobsil at DS3 (Fig. 5a). In leaves of Yeobsil or PD6D 4-1-1, PfFAD7-1 and PfFAD7-2 were expressed at higher levels than PfFAD2 and PfFAD3. PCD6DES was expressed at low levels similar to those of PfFAD2 and PfFAD3 (Fig. 5b). Bar (Basta resistance) was expressed during DS3 and in leaves of PD6D 4-1-1, but not in either DS3 or leaves of Yeobsil (Fig. 5a, b). In particular, the expression level of bar was much higher (54.7-fold) than that of other genes in PD6D 4-1-1 leaves (Fig. 5b). We also determined the expression level of PcD6DES gene in DS1 to DS4 and leaf. The expression of PcD6DES gene in PD6D 4-1-1 was low in DS1 to DS2 and very high in DS3 to DS4 (Fig. 5c). PcD6DES gene was also highly expressed in leaf tissue more than expected. No expression was detected in all Yeobsil samples.

\section{Fatty acid composition in PcD6DES transgenic perilla leaves}

To investigate the changes in fatty acid composition in PD6D leaves, we analyzed the fatty acid composition of 4-week-old leaves from $\mathrm{T}_{2}$ homozygous transgenic plants. Unlike the fatty acid composition of perilla seeds, leaves contained much higher levels of C16 fatty acids and LA but lower levels of oleic acid and ALA (Table 3). Although the expression of $P c D 6 D E S$ was driven by the seed-specific vicilin promoter from Pisum sativum [34], GLA and SDA were still synthesized and accumulated in PD6D leaves, albeit at a lower proportion than in seeds (Table 3). PD6D seeds showed similar proportions of fatty acids among PD6D homozygous lines (PD6D \#1-3, \#2-3, \#3-3, \#4-1) (Table 2). However, PD6D leaves exhibited different proportions of the fatty acids LA, GLA and ALA among PD6D homozygous lines, and $\mathrm{C} 18: 2 \Delta^{6,9}$ was not detected in leaves (Table 3).

\section{Fatty acid composition in developing seeds from PCD6DES transgenic perilla}

GLA and SDA accumulated to high levels in PD6D mature seeds. We measured GLA and SDA, as well as fatty acids, at different stages of seed development to determine how the compositions of these molecules changed throughout seed development (Table 4). During early seed development in Yeobsil, saturated fatty acid content was relatively high compared to the late stage. In addition, the proportions of LA and GLA were similar. However, as the seeds approached the late stage of development, saturated fatty acid contents

Table 2 Fatty acid composition of mature D6DES T 2 perilla (PD6D) seeds. Data represent mole\% of fatty acid methyl esters. Experiments were performed in triplicate, and the mean values are given

\begin{tabular}{|c|c|c|c|c|c|c|c|c|c|}
\hline Fatty acid & Yeobsil & PD6D 1-1 & PD6D 1-3 & PD6D 2-1 & PD6D 2-3 & PD6D 3-1 & PD6D 3-3 & PD6D 4-1 & PD6D 4-3 \\
\hline C16:0 & 7.7 & 7.3 & 7.1 & 7.2 & 7.2 & 7.3 & 7.6 & 7.5 & 7.3 \\
\hline C18:0 & 2.4 & 2.6 & 2.6 & 2.3 & 2.4 & 2.7 & 2.7 & 2.4 & 2.2 \\
\hline $\mathrm{C} 18: 1 \Delta^{9}$ & 18.5 & 15.7 & 14.4 & 12.9 & 14.7 & 14.2 & 13.3 & 13.7 & 12.6 \\
\hline$C 18: 2 \Delta^{6,9}$ & - & 1.6 & 2.0 & 0.7 & 1.8 & 1.1 & 1.7 & 1.8 & 0.6 \\
\hline LA & 11.5 & 9.3 & 8.1 & 9.8 & 8.6 & 10.4 & 7.7 & 7.2 & 11.6 \\
\hline GLA & - & 16.7 & 24.9 & 15.9 & 24.6 & 16.8 & 24.8 & 24.4 & 14.2 \\
\hline ALA & 60.1 & 29.9 & 20.8 & 32.8 & 21.0 & 30.2 & 21.0 & 21.5 & 37.6 \\
\hline SDA & - & 16.9 & 20.2 & 18.5 & 19.7 & 17.4 & 21.1 & 21.5 & 13.8 \\
\hline D6DES products & - & 35.1 & 47.0 & 35.1 & 46.1 & 35.3 & 47.6 & 47.7 & 28.7 \\
\hline
\end{tabular}




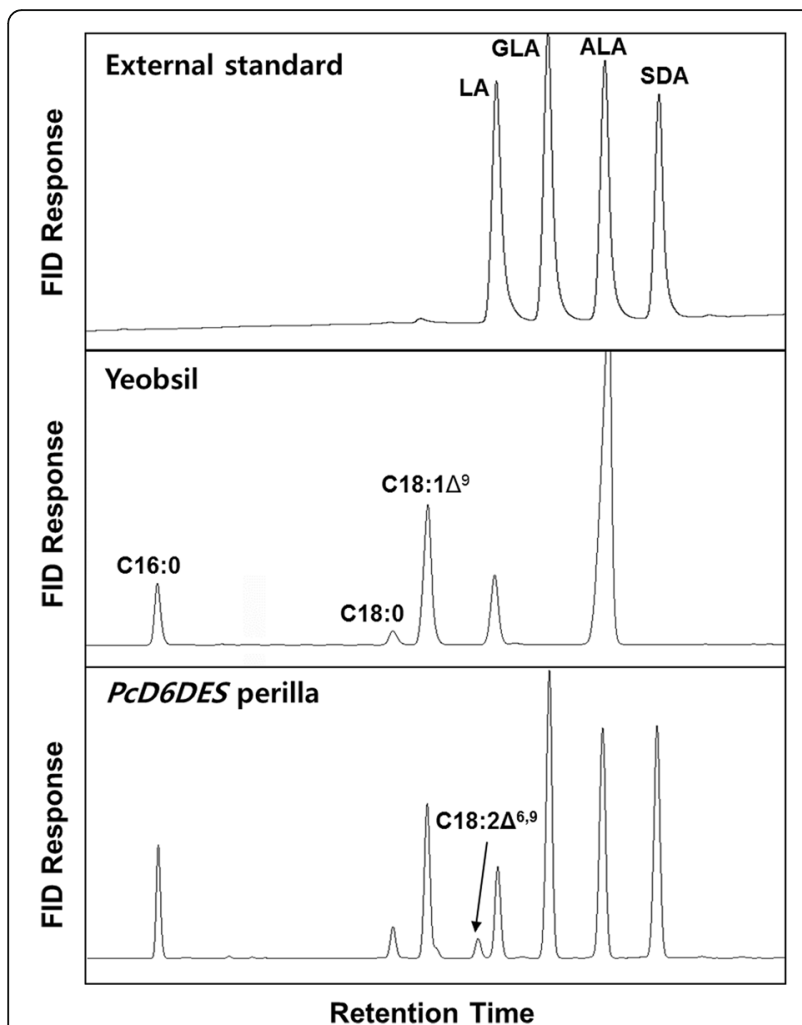

Fig. 3 Chromatogram of PCD6DES perilla analyzed by GC. External standard for the mixture of LA, GLA, ALA and SDA was transmethylated. Yeobsil perilla seeds contain common fatty acids C16:0, C18:0, C18:1 $\Delta^{9}$, LA and ALA. PCD6D transgenic perilla seeds contain $C 18: 2 \Delta^{6,9}$, GLA and SDA, which are absent in Yeobsil

became lower and a large proportion of LA was converted to ALA. The fatty acid composition in developing seed stage 1 (DS1) and the mature stage DS4 resembled that of mature perilla leaves. The saturated fatty acid content in PD6D DS1 was almost the same as that in Yeobsil DS1. During late seed development, saturated fatty acid contents were lower and PUFAs contents were higher than at the early stage in both Yeobsil and PD6D.

The change in the proportions of PUFA during seed development in Yeobsil and PD6D are shown in Table 4 and Fig. 6. In Yeobsil, the proportions of LA and ALA were similar in DS1, and after DS1, LA levels gradually decreased, whereas ALA levels gradually increased (Table 4, Fig. 6a). In PD6D seeds, the proportions of fatty acids did not differ from those of Yeobsil in DS1. However, after DS1, the proportion of ALA decreased and SDA increased at the expense of ALA. In addition, the proportion of LA was lower than that of Yeobsil, and GLA appeared to be produced from LA (Table 4, Fig. 6b). PUFAs were diversified, and the degree of unsaturation became higher in PD6D seeds, which is similar to Yeobsil at all stages of seed development (Fig. 6c).
Fatty acid analysis of neutral lipids and polar lipids in mature perilla seeds

To investigate the differences in fatty acid compositions of polar lipids and neutral lipids from mature Yeobsil and PD6D (DS4) seeds, we extracted total lipids from the seeds, separated them using TLC (Additional file 2: Figure S4) and analyzed the fatty acid composition of each lipid using GC. The fatty acid compositions of neutral lipids, TAG, diacylglycerol and polar lipids were analyzed separately. The fatty acid composition of polar lipids in mature Yeobsil DS4 seeds was similar to that at DS1 (Tables 4 and 5). The polar lipids from mature PD6D seeds contained more GLA and SDA than those of PD6D DS1 (Table 5). GLA and SDA associated more with neutral lipids than with polar lipids in PD6D but were not detected in Yeobsil seeds.

\section{Seed weight and seed oil content of transgenic PCD6DES perilla}

To investigate the characteristics of transgenic PcD6DES perilla seeds compared with Yeobsil seeds, we measured seed weight and oil content. We weighed 100 seeds three times and calculated the average seed weights. The seed weight of Yeobsil was the highest $(4.70 \mathrm{mg} / \mathrm{seed})$, and average seed weight of $T_{2}$ perilla seeds was slightly less (4.36 $\mathrm{mg} / \mathrm{seed}$; 4.09-4.52 mg/seed) than Yeobsil seeds (Fig. 7a). The seed weights measured in this study are similar to those reported by Asif [22]. Meanwhile, the seed oil content showed different trends compared to seed weight. The fatty acid contents in PD6D seeds were $397.6 \mu \mathrm{g} / \mathrm{mg}$ seeds and was similar or $3.3-3.6 \%$ higher than that of Yeobsil seeds. The fatty acid contents in PD6D 1-3-1, 3-3-2 and 4-1-1 were 398.9, 410.6 and $411.8 \mu \mathrm{g} / \mathrm{mg}$ seeds, respectively (Fig. $7 \mathrm{~b})$, and the average seed oil content was $407.1 \mu \mathrm{g} / \mathrm{mg}$ seeds. Based on these data, the FAME levels per seed were as follows: Yeobsil, $1.87 \mathrm{mg}$ FAME/seed; PD6D 1-3-1, 1.80 mg FAME/seed; PD6D 3-3-2, 1.84 mg FAME/seed; PD6D 4-4-1, $1.68 \mathrm{mg}$ FAME/seed. The FAME levels per seed in the PD6D lines were almost the same or $89.8 \%$ those of Yeobsil seeds. The total seed oil content was approximately $40 \%$ in perilla, which is in agreement with the data from Asif [22] and Shin and Kim [24]. Compared to Yeobsil, the seed weight of PD6D was slightly lower, but these seeds possessed slightly higher oil contents.

\section{Discussion}

In this study, we characterized PcD6DES, the first D6DES identified in Phytophthora spp., and found it to resemble other known fatty acid desaturases. PcD6DES contains cytochrome b5 domain, three histidine boxes and six TM domains (Fig. 1). Thus, we conclude that PcD6DES encodes a protein with characteristics of a 'front-end' fatty acid desaturase.

Saccharomyces cerevisiae has only one fatty acid desaturase, Ole1p which catalyzes the conversion C16:0 and 
A

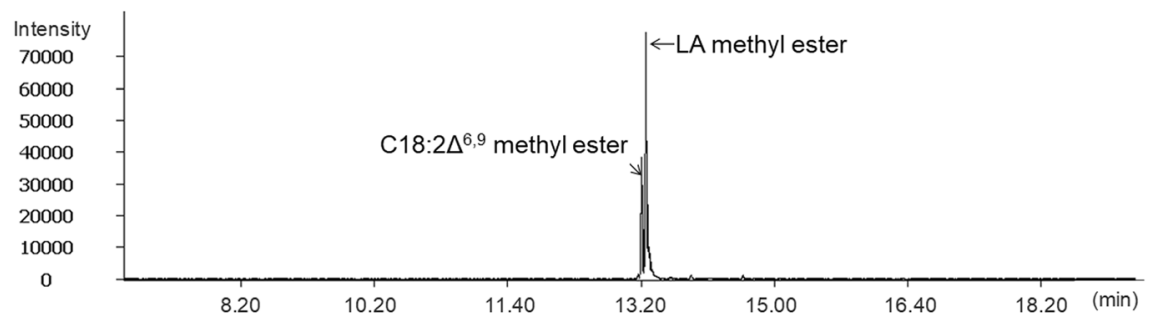

B
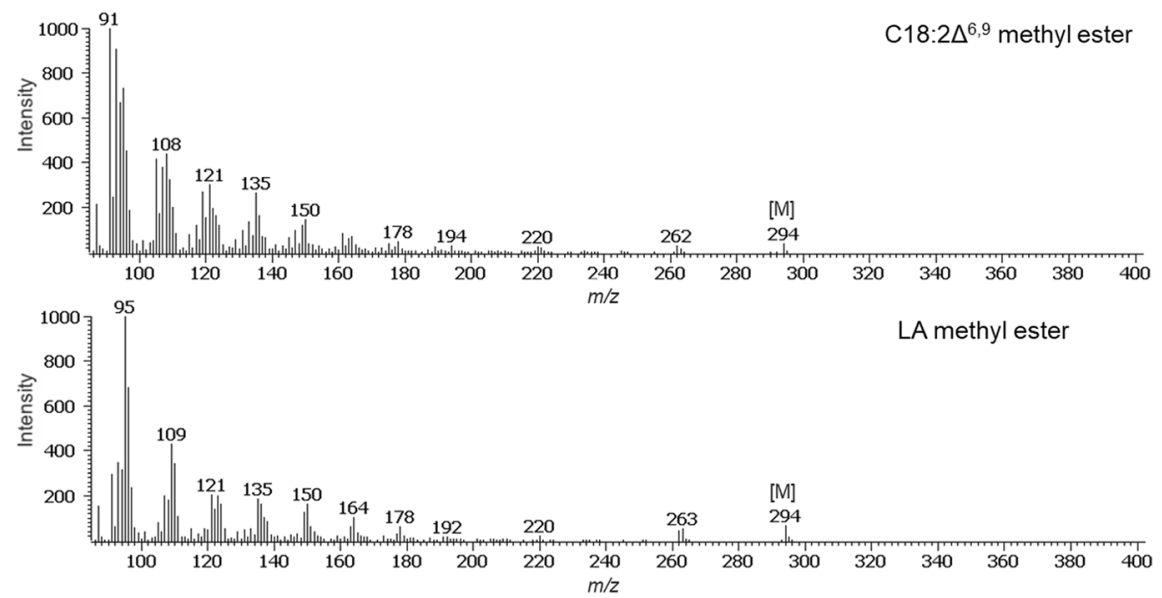

Fig. 4 Selected-ion chromatogram and mass spectra for LA methyl ester and putative C18:2 $\Delta^{6,9}$ methyl ester (molecular mass: 294) from PCD6DES perilla seed. a Selected-ion chromatogram for $\mathrm{m} / \mathrm{z} 294$ and (b) mass spectra of LA methyl ester and putative C18:2 $\Delta^{6,9}$ methyl ester as methyl ester derivatives separated on a 30 m*0.25 mm i.d. fused-silica capillary column coated with $0.25 \mu \mathrm{m}$ CP-SIL 8 CB Low Bleed

$\mathrm{C} 18: 0$ into $\mathrm{C} 16: 1 \Delta^{9}$ and $\mathrm{C} 18: 1 \Delta^{9}$, respectively [35]. Therefore, $S$. cerevisiae contains mainly four kinds of fatty acids, $\mathrm{C} 16: 0, \mathrm{C} 16: 1 \Delta^{9}, \mathrm{C} 18: 0$ and $\mathrm{C} 18: 1 \Delta^{9}$. Functional characterization of PcD6DES in budding yeast

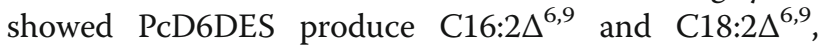
although the proportion of $\mathrm{C} 18: 2 \Delta^{6,9}$ was barely detectable (Table 1). This result suggests that PcD6DES might have a weak affinity for monounsaturated fatty acids, including $\mathrm{C} 16: 1 \Delta^{9}$ and $\mathrm{C} 18: 1 \Delta^{9}$ (Table 1). The ratios of saturated fatty acids to unsaturated fatty acids did not differ much from those of yeast cultured with LA and/or ALA and without LA and/or ALA. These results likely indicate that fatty acid metabolism is regulated in yeast cells to maintain the appropriate levels of unsaturated fatty acids while they take up unsaturated fatty acids. However, unlike the fatty acid composition of budding yeast expressing $P c D 6 D E S$, we detected $C 18: 2 \Delta^{6,9}$ in PCD6DES perilla seeds (Fig. 3). This is likely because perilla seed oil contains little $\mathrm{C} 16: 1 \Delta^{9}$ and relatively high levels of $C 18: 1 \Delta^{9}$, which is consistent with reports describing the detection of $\mathrm{C} 18: 2 \Delta^{6,9}$ in transgenic oilseed crops expressing a fungal D6DES [12, 13].

The sum of GLA and SDA levels from each progeny of the same $\mathrm{T}_{0}$ plant was highly variable (Table 2, Additional file 1: Table S3). We divided the progenies into those with high and low contents of D6DES product, which we attributed to the presence of the transgene in a homozygous vs. hemizygous state. The results of genotyping by Basta treatment supported this hypothesis (Additional file 1: Table S3). Under Basta treatment, seedlings of the high GLA and SDA lines (putative homozygous lines) all survived, whereas those of low GLA and SDA lines (putative hemizygous lines) showed a 3:1 segregation ratio (Additional file 1: Table S3). Therefore, it appears GLA and SDA contents depend on zygosity, with higher levels seen in homozygous plants and lower levels detected in hemizygous plants.

PcD6DES was expressed and PcD6DES products accumulated not only in seeds but also in leaves of transgenic perilla (Table 3; Fig. 5), despite PcD6DES being expressed from a seed-specific vicilin promoter. It is hard to conclude vicilin promoter shows leaky expression pattern because the expression pattern of vicilin promoter from Pisum sativum has not been reported. We supposed a few possibilities which results in this phenomenon. First, vicilin promoter from Pisum sativum might be originally leaky promoter which is not regulated tightly. Second, when vicilin promoter moved to perilla from pea, it may not be spatially regulated in the same manner as it is in native species. There was a 


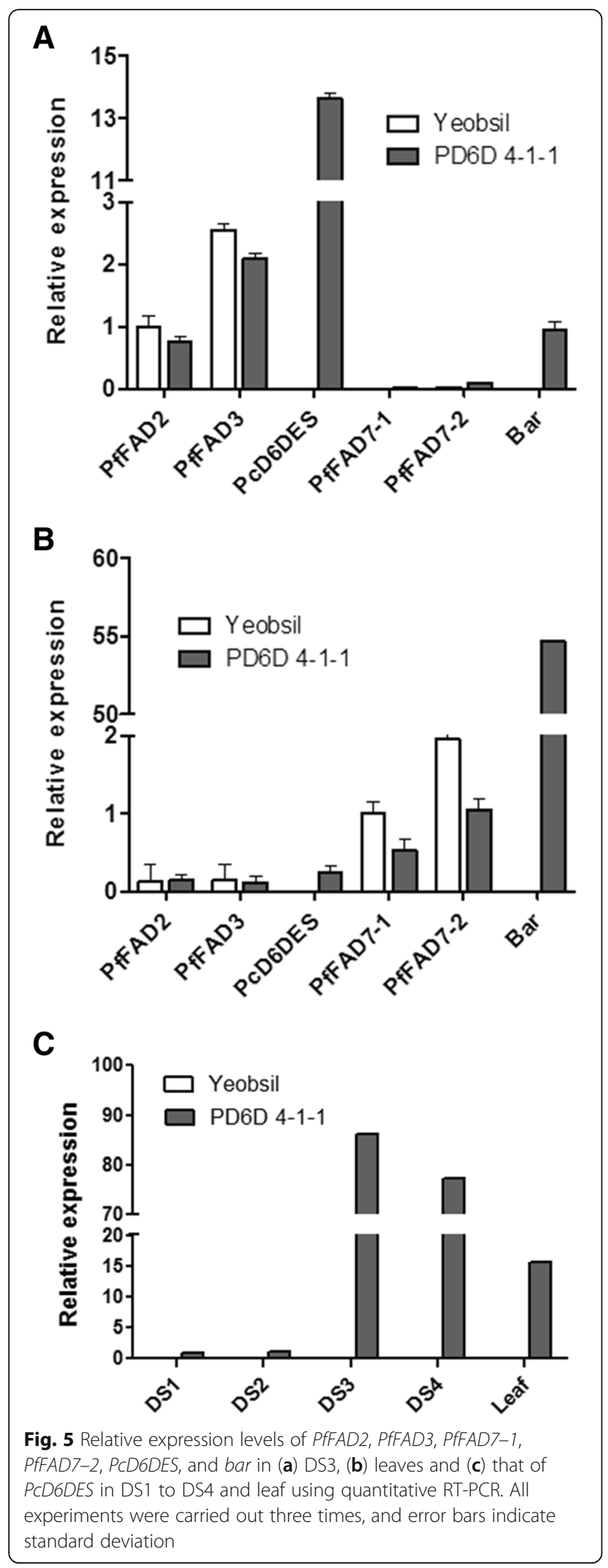

Table 3 Fatty acid composition of leaves from D6DES $T_{2}$ perilla (PD6D) and Yeobsil plants. Data represent mole\% of fatty acid methyl esters. Experiments were performed in triplicate, and the mean values are shown

\begin{tabular}{|c|c|c|c|c|c|}
\hline Fatty acids & Yeobsil & $\begin{array}{l}\text { PD6D 1-3- } \\
1\end{array}$ & $\begin{array}{l}\text { PD6D 2-3- } \\
2\end{array}$ & $\begin{array}{l}\text { PD6D 3-3- } \\
2\end{array}$ & $\begin{array}{l}\text { PD6D 4-1- } \\
1\end{array}$ \\
\hline C16:0 & 25.5 & 21.5 & 22.2 & 24.7 & 20.4 \\
\hline $\mathrm{C} 16: 1 \Delta^{3 \mathrm{t}}$ & 3.3 & 3.2 & 3.2 & 3.1 & 2.8 \\
\hline C16:2 & 0.9 & 0.5 & 0.6 & 0.6 & 0.4 \\
\hline C16:3 & 2.5 & 3.1 & 3.4 & 3.7 & 3.3 \\
\hline C18:0 & 3.3 & 4.5 & 4.3 & 4.0 & 4.4 \\
\hline $\mathrm{C} 18: 1 \Delta^{9}$ & 4.1 & 3.5 & 3.6 & 4.1 & 3.3 \\
\hline LA & 23.0 & 14.5 & 13.9 & 11.3 & 9.5 \\
\hline GLA & - & 6.0 & 8.8 & 10.1 & 6.7 \\
\hline ALA & 35.7 & 37.3 & 33.1 & 31.9 & 42.9 \\
\hline SDA & - & 4.2 & 5.1 & 5.1 & 4.9 \\
\hline C20:0 & 1.8 & 1.9 & 1.8 & 1.6 & 1.5 \\
\hline $\begin{array}{l}\text { D6DES } \\
\text { products }\end{array}$ & 0.0 & 10.1 & 13.9 & 15.2 & 11.6 \\
\hline Total PUFA & 62.1 & 65.5 & 64.8 & 62.5 & 67.7 \\
\hline
\end{tabular}

report when the seed-specific promoters from wheat and barley directed the expression of green fluorescence protein, the expression was leaky [36]. Third, when T-DNA harboring the expression cassette of PcD6DES under the control of vicilin promoter was integrated into perilla genome, the spatial regulation of PcD6DES expression might be changed by positional effect. Although the expression of the vicilin promoter does not appear to be entirely exclusive to seed tissue, the expression of PCD6DES was 47.6-fold higher in seeds than in leaves. Seeds contained much higher levels of substrates for PcD6DES (71.6\%) than leaves (58.7\%) (Tables 2 and 3). This difference is likely due to the varied PcD6DES expression levels and the differential availability of precursor contents between seeds and leaves. When the borage $D 6 D E S$ gene was expressed under the control of the cauliflower mosaic virus $35 \mathrm{~S}$ promoter in tobacco (Nicotiana tabacum), the levels of substrates and products of D6DES were 74.2 and $22.8 \%$, respectively, and the conversion rate was $31.5 \%$ [20]. Meanwhile, in the current study, the levels of substrates and products of D6DES in transgenic perilla leaves were 58.7 and $15.2 \%$, respectively, and the conversion rate was $26.0 \%$ (Table 3 ). This difference is likely because the constitutive $35 \mathrm{~S}$ promoter drove $D 6 D E S$ expression more strongly in leaves than the seed-specific promoter used in the current study, as well as the higher substrate content in tobacco leaves than in perilla leaves. Overall, these results support our findings described above.

In the fatty acids of perilla leaves, $\mathrm{C} 16: 1 \Delta^{3 \mathrm{t}}$ is produced by FAD4 in chloroplasts [37]. D6DES can convert 
Table 4 Fatty acid composition of developing seeds from PCD6DES T 2 perilla (PD6D) and Yeobsil plants. Data represent mole\% of fatty acid methyl esters. Experiments were repeated in triplicate, and the mean values are given

\begin{tabular}{|c|c|c|c|c|c|c|c|c|}
\hline \multirow{2}{*}{$\begin{array}{l}\text { Fatty } \\
\text { acid }\end{array}$} & \multicolumn{4}{|c|}{ Yeobsil } & \multicolumn{4}{|c|}{ PD6D 4-1-1 } \\
\hline & DS1 & DS2 & DS3 & DS4 & DS1 & DS2 & DS3 & DS4 \\
\hline C16:0 & 21.9 & 20.4 & 12.1 & 8.2 & 21.8 & 19.3 & 11.9 & 8.0 \\
\hline C18:0 & 6.2 & 6.5 & 2.5 & 2.1 & 6.3 & 6.9 & 2.6 & 2.0 \\
\hline $\mathrm{C} 18: 1 \Delta^{9}$ & 6.0 & 5.9 & 10.1 & 10.7 & 5.0 & 5.4 & 8.8 & 11.9 \\
\hline$C 18: 2 \Delta^{6.9}$ & - & - & - & - & - & - & 0.3 & 0.9 \\
\hline LA & 32.3 & 30.4 & 19.5 & 18.6 & 32.7 & 28.9 & 14.4 & 7.8 \\
\hline GLA & - & - & - & - & 2.2 & 3.1 & 18.0 & 25.4 \\
\hline ALA & 33.7 & 36.9 & 55.8 & 60.4 & 30.3 & 32.0 & 25.3 & 22.0 \\
\hline SDA & - & - & - & - & 1.7 & 4.4 & 18.7 & 22.0 \\
\hline
\end{tabular}

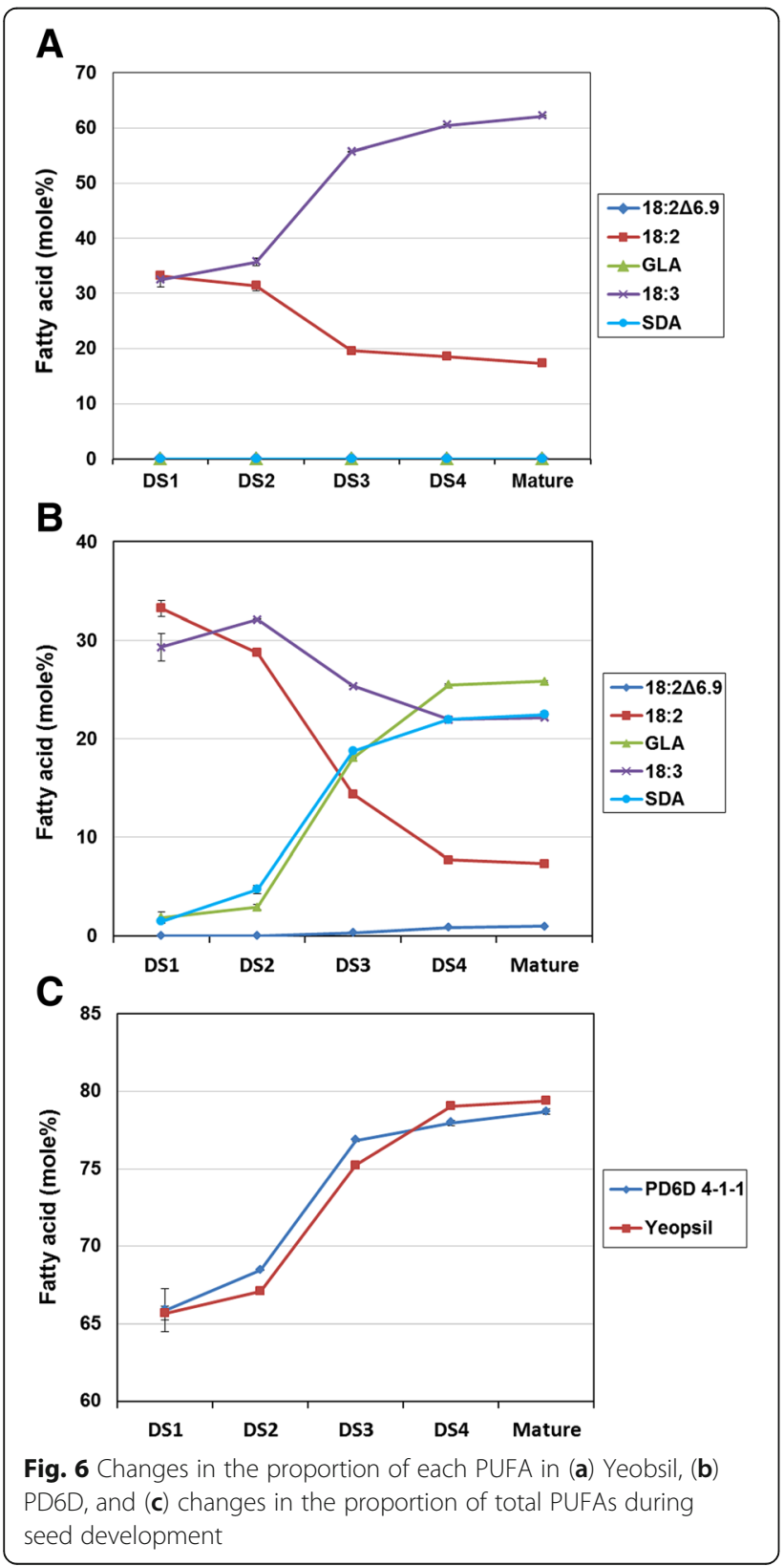

$\mathrm{C} 16: 1 \Delta^{9}$ and $\mathrm{C} 18: 1 \Delta^{9}$ into $\mathrm{C} 16: 2 \Delta^{6,9}$ and $\mathrm{C} 18: 2 \Delta^{6,9}$, respectively, in budding yeast (Fig. 2). Therefore, C16:1 $\Delta^{3 \mathrm{t}}$, not a substrate for D6DES, is not converted into $\mathrm{C} 16: 2 \Delta^{6,9}$.

The fatty acid compositions of DS1 and polar lipids in mature seeds in Yeobsil were similar (Tables 4 and 5). Seeds at the early stage of development contain little TAG [23], instead mainly containing polar lipids. On the contrary, PD6D did not reflect this trend. PcD6DES products are thought to accumulate in polar lipids of mature PD6D seeds during seed development. The fatty acid compositions from DS4 and neutral lipids of mature seeds in both PD6D and Yeobsil were similar (Tables 4 and 5), likely because almost all seed oil comprises neutral lipids. Given that polar lipids incorporate more 16:0 at $s n-1$ position than TAG [38], polar lipids and DS1 contains more 16:0 than DS4 and neutral lipids (Tables 4 and 5). Severe alteration of 16:0 from DS1 to DS4 was not by D6DES but by the relative proportion change of polar lipids and TAG. SDA of DS4 was gradually increased in PD6D because TAG content of DS4 is higher than earlier stage. TAG contains higher PUFAs than

Table 5 Fatty acid composition of neutral lipids and polar lipids from mature perilla seeds. Data represent mole\% of fatty acid methyl esters. Experiments were repeated in triplicate, and the mean values are presented

\begin{tabular}{llllll}
\hline & \multicolumn{2}{l}{ Polar lipids } & & \multicolumn{2}{l}{ Neutral lipids } \\
\cline { 2 - 3 } & Yeobsil & PD6D 4-1-1 & & Yeobsil & PD6D 4-1-1 \\
\hline C16:0 & 20.2 & 22.2 & & 7.8 & 7.4 \\
C18:0 & 7.2 & 7.9 & & 2.3 & 2.3 \\
C18:1 $\Delta^{9}$ & 6.8 & 9.1 & & 11.6 & 13.3 \\
C18:2 $\Delta^{6.9}$ & - & - & & - & 1.3 \\
LA & 30.1 & 19.1 & & 17.6 & 7.2 \\
GLA & - & 15.7 & & - & 25.9 \\
ALA & 35.7 & 19.8 & & 60.8 & 21.8 \\
SDA & - & 6.2 & & - & 20.8 \\
\hline
\end{tabular}



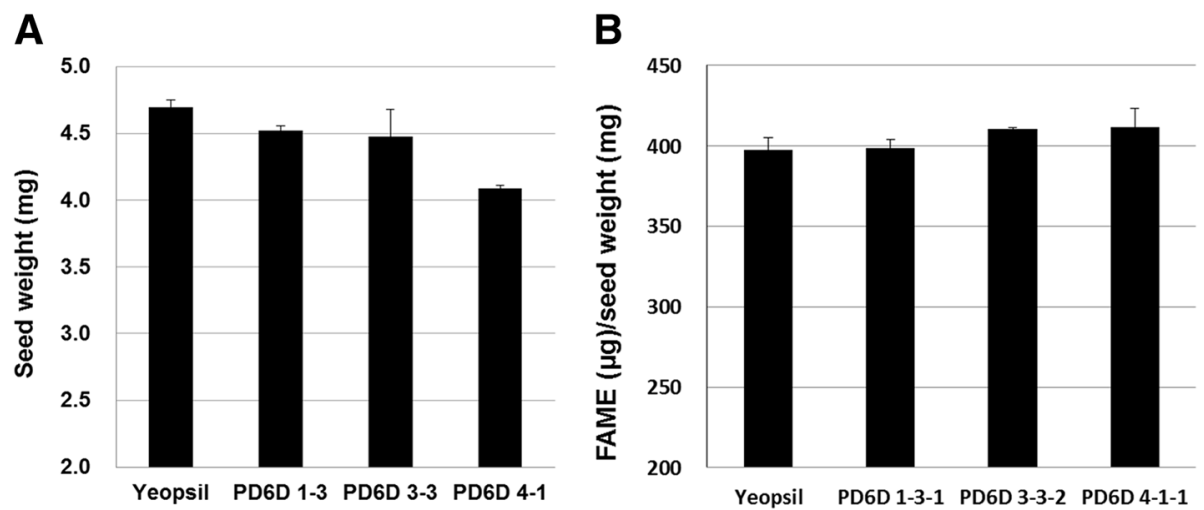

Fig. 7 Analysis of (a) weight and (b) oil content of 100 WT perilla and PCD6DES perilla seeds. All experiments were performed in triplicate, and error bars indicate standard deviation

polar lipids in perilla (Table 5). In Table 4, Yeobsil DS4 contains more PUFAs than Yeobsil DS1. Thus, PD6D DS4 contains more GLA and SDA than PD6D earlier stage. The fatty acid composition of polar lipids from mature seeds indicated that GLA and SDA associate with membrane lipids and could not be completely transferred to TAG (Table 5).

The levels and patterns of PfFAD2, PfFAD3, PfFAD7-1 and PfFAD7-2 expression coincided with the previous report [33]. The expression levels of endogenous genes, including PfFAD2 and PfFAD3 in DS3 and PfFAD7-1 and PfFAD7-2 in leaves, were lower in PD6D than in Yeobsil (Fig. 5a, b). Perhaps the high expression levels of PcD6DES and bar genes in DS3 and leaves, respectively, influence the endogenous genes responsible for the synthesis of PUFAs and lowered their expression. The expression level of PcD6DES gene in PD6D 4-1-1 is much higher in late stage than early stage (Fig. 5c). This result is in accordance with the expression of seed storage protein. The PcD6DES products of developing seeds in PD6D 4-1-1 were low in DS1 (3.9\%) and DS2 (7.5\%) but dramatically increased in DS3 (37.0\%) and DS4 (48.3\%) (Table 4). The fatty acid analysis of developing seeds in PD6D 4-1-1 is consistent with the expression level of developing seeds in PD6D 4-1-1.

The most common omega- 3 and omega- 6 fatty acids in vegetable oil are ALA and LA, respectively. Notably, these fatty acids are essential for human health. Vegetable oils from oilseed crops such as corn, sunflower, safflower, sesame, cottonseed and soybeans contain high levels of omega- 6 fatty acid but little omega- 3 fatty acid. If the ratio of omega- 3 to omega- 6 fatty acids decreases below the recommended 1:4 ratio due to the overconsumption of omega- 6 fatty acid oil or cooking food in omega- 6 fatty acid, there could be detrimental consequences to health [39]. Studies have shown that a high intake of omega- 6 fatty acids increases blood viscosity, vasospasm and vasoconstriction and decreases bleeding time [39]. The ratio between omega- 3 and omega- 6 in PD6D seed oil is 1.35:1, which certainly exceeds the healthy recommended ratio. Moreover, PD6D is more beneficial to health because it can bypass the rate-limiting step from ALA to SDA, allowing SDA to be more efficiently converted to DHA [3].

In PD6D seed oil, GLA and SDA accumulated to levels of up to 24 and $21 \%$, respectively (Table 2 ). By contrast, borage seeds contain $20-25 \%$ GLA, and evening primrose seeds contain 10\% GLA, but they do not contain SDA [20]. Blackcurrant seeds contain 15.8\% GLA and approximately $2 \%$ SDA [40, 41], and hemp seeds contain $3.6 \%$ GLA and 2-3\% SDA [10, 42]. Echium seeds contain $11.8 \%$ GLA and 13\% SDA, which is the highest SDA content in natural land plants [43]. While the sum of GLA and SDA from the plant seeds described above is up to 25\%, PD6D seeds contain a similar amount of GLA to borage and a higher content of SDA than echium (Table 2).

The seed weight in perilla measured in the current study ( $4 \mathrm{mg})$ was similar to that measured by Asif [22]. We detected a seed oil content of approximately $40 \%$ in perilla, which is also in agreement with previous results $[22,24]$. Indeed, the introduction of fatty acid desaturase genes such as D6DES has not previously been shown to increase seed weight or seed oil content. Furthermore, transgenic plants generally demonstrate poor agronomic performance in traits other than their modified target traits. In PCD6DES perilla with the beneficial transgene activity the overall plant phenotype was similar to that of Yeobsil.

There have been several reports of transgenic plants accumulating GLA and/or SDA in their seeds via the use of a D6DES transgene alone or in tandem with other fatty acid desaturase genes. In an early study, the expression of D6DES from cyanobacteria in transgenic tobacco resulted in GLA and SDA accumulation in seed oil [44]. This was the first report of the biotechnological 
production of GLA and SDA in transgenic plants. Later, transgenic tobacco constitutively expressing D6DES from borage (Borago officinalis) was found to accumulate 13\% GLA and 10\% SDA in its seeds [20]. In addition, canola plants coexpressing D6DES from the oleaginous fungus Mortierella alpina and $\Delta 12$ desaturase gene (Brassica napus) specifically in their seeds produced $40 \%$ GLA [12]. Similarly, when D6DES from the oleaginous fungus Pythium irregulare was expressed under the control of the seed-specific napin promoter in Brassica juncea, GLA comprised $40 \%$ of seed oil [13]. When the borage D6DES gene and Arabidopsis $\triangle 15$ desaturase gene were coexpressed in soybean driven by the soybean seed-specific $\beta$-conglycinin promoter, SDA accumulated to $29 \%$ of seed oil content [45]. Linseed expressing the SDA-specific D6DES gene from Primula vialii under the control of the Vicia faba seed-specific USP promoter had a 13\% SDA content in its seed oil [15]. More recently, when the D6DES gene from the protozoan Saprolegnia diclina was expressed under the control of the Arabidopsis OLEOSIN promoter in safflower, GLA accumulated to $77 \%$ of the seed oil content, i.e., the highest reported GLA content for transgenic safflower [46]. It is important to note that the GLA levels in transgenic seed oil reported by Liu et al. [12], Hong et al. [13] and Nykiforuk et al. [46] were higher than those found in the current study. Furthermore, the SDA content in transgenic seed oil reported by Eckert et al. [45] was also higher than we achieved. However, the results of Liu et al. [12] and Eckert et al. [45] were achieved via coexpression of $D 6 D E S$ and another desaturase gene, and there has been no report of higher GLA and SDA production in transgenic seed oil due to the introduction of a single gene. In addition, the production of perilla seeds containing $47.7 \%$ D6DES products (GLA, SDA and C18:2 $\Delta^{6,9}$ ) due to the incorporation of only $D 6 D E S$ gene represents a dramatic improvement (Table 2).

Looking forward, SDA could be produced at very high levels if the ALA-preferred D6DES were introduced into perilla. For example, D6DES enzymes from Primula vialii and Primula luteola showed high ALA substrate specificity and produced SDA exclusively [14, 47]. Furthermore, perilla that produces very high levels of SDA could be used to produce EPA and DHA by introducing fatty acid elongase, $\Delta 5$ desaturase and $\Delta 4$ desaturase.

\section{Conclusions}

Two decades have been spent creating transgenic plants that produce higher levels of expensive functional fatty acids such as GLA and SDA in their seeds beyond what wild plants are capable of producing. In this study, we developed transgenic perilla with the very high content over $45 \%$ of both GLA and SDA. These plants might serve as an important resource for producing omega-3 oil capsules as health food and promoting human health. In addition, other genes could be added to these plants to create transgenic perilla that produce fish-oil-like oil in their seeds and provide further health benefits.

\section{Additional files}

Additional file 1: Table S1. Primers used in this study. Nucleotide symbols are as follows: $Y, C / T ; R, G / A ; W, A / T ; D, G / A / T ; N, A / T / G / C$. Table S2. Segregation ratio of D6DES $T_{1}$ perilla plants treated with Basta. Table S3. Genotyping of D6DES $T_{2}$ perilla plants treatment with Basta. (ZIP 3970 kb)

Additional file 2: Figure S1. Vector constructs containing the PCD6DES gene. (A) Vector for yeast transformation. PGAL1 and CYS TT represent galactose-inducible GAL1 promoter and CYC1 transcriptional terminator, respectively. URA encodes a biosynthetic enzyme of uracil, as a marker gene for yeast selection. Amp ${ }^{R}$ encodes $\beta$-lactamase that inactivates antibiotics ampicillin, as a marker gene for $E$. coli selection. (B) Vector for plant transformation. PCAMBIA3300 was used as a backbone vector. Pvic and Tocs indicate vicilin promoter and octopine synthase III terminator, respectively. $L B$ and $\mathrm{RB}$ represent left border and right border, respectively. Each box represents a gene expression cassette. $\mathrm{B}, \mathrm{BamHl}$; C, Clal; H3, Hindlll; K, Kpnl; N, Notl; P, Pstl; R1, EcoRl; Sc, Sacl; X, Xbal, $\mathrm{X}$, Xhol. Figure S2. The predicted transmembrane domains of fatty acid desaturases including (A) Phytophthora citrophthora D6DES, (B) evening primrose (Oenothera biennis) D6DES (GenBank accession No. EU416278) and (C) Perilla frutescens var. frutescens FAD2 (GenBank accession No. KP070823) by TOPCONS. Figure S3. The expression from PCD6DES gene in RNA level from S. cerevisiae. RT-PCR from total RNAs of PCD6DES yeast. PYES2 is yeast cells harboring a blank vector as an negative control. PCD6DES is yeast cells carrying PYES2-PCD6DES. ScAct1 is a reference gene from $S$. cerevisiae actin gene (GenBank accession No. L00026). - and + indicate non-induction and induction, respectively. The induction method of yeast was described in Methods section. M, 1 kb DNA ladder. Figure S4. TLC analysis of lipids extracted from perilla mature seeds. The lipids were developed and visualized under the ultra violet after the primuline spraying. The spots corresponding neutral lipids (TAG and DAG) and polar lipids were scraped off and the fatty acid composition was analyzed with GC. The method using this experiment is described in the 'Thin layer chromatography (TLC)' subsection of Methods section (ZIP 537 kb)

\section{Abbreviations}

ALA: a-linolenic acid; D6DES: $\Delta 6$ desaturase; DHA: cis-4,7,10,13,16,19docosahexaenoic acid; DS: developing seed stage; EPA: cis-5,8,11,14,17eicosapentaenoic acid; FID: flame ionization detector; GLA: $\gamma$-linolenic acid; LA: linoleic acid; SDA: stearidonic acid; TM: transmembrane domain; VLCPUFA: very long chain polyunsaturated fatty acid

\section{Acknowledgements}

Not applicable.

\section{Funding}

The overall process of this research was supported by a research grant of Rural Development Administration's project (Project No. PJ01257102, K-RL), Republic of Korea, and the TLC data analysis was separately supported by the Mid-Career Researcher Program of the National Research Foundation of Korea (NRF-2017R1A2B4007096, HUK), Republic of Korea.

\section{Availability of data and materials}

The sequence of PCD6DES gene from this study has been deposited to the NCBI GenBank (https://www.ncbi.nlm.nih.gov/genbank/) as an accession No. DQ836059.

\section{Authors' contributions}

K-HK performed gene cloning, functional analysis in yeast and Perilla transformation; K-RL, JBK, JKK carried out the fatty acid analysis; S-BH screened the Phytophthora strain; K-RL, IJ conducted qRT-PCR and TLC 
experiments; MHL raised perilla plants to supply seeds for transformation; KRL, K-HK, HUK analyzed the data; K-RL, K-HK wrote the paper. All authors read and approved the final manuscript.

\section{Ethics approval and consent to participate} Not applicable.

\section{Consent for publication}

Not applicable.

\section{Competing interests}

The authors declare that they have no competing interests.

\section{Publisher's Note}

Springer Nature remains neutral with regard to jurisdictional claims in published maps and institutional affiliations.

\section{Author details}

${ }^{1}$ Department of Agricultural Biotechnology, National Institute of Agricultural Science, RDA, Jeonju 54874, Jeollabukdo, Republic of Korea. ${ }^{2}$ Department of Agro-food Resources, National Institute of Agricultural Science, RDA, Wanju-gun, Jeollabukdo, Republic of Korea. ${ }^{3}$ Department of Agricultural Biology, National Institute of Agricultural Science, RDA, Wanju-gun, Jeollabukdo, Republic of Korea. ${ }^{4}$ Department of Bioindustry and Bioresource Engineering, Plant Engineering Research Institute, Sejong University, Seoul 05006, Republic of Korea. ${ }^{5}$ Department of Southern Area Crop Science, National Institute of Crop Science, Miryang, Gyeongsangnamdo, Republic of Korea. ${ }^{6}$ Division of Life Sciences, Incheon National University, Incheon, Republic of Korea.

\section{Received: 9 July 2018 Accepted: 12 March 2019}

Published online: 01 April 2019

\section{References}

1. Kapoor R, Huang YS. Gamma linolenic acid: an antiinflammatory omega-6 fatty acid Curr Pharm Biotechnol. 2006;7:531-4. https:/doi.org/10.2174/138920106779116874.

2. Kawamura A, Ooyama K, Kojima K, Kachi H, Abe T, Amano K, Aoyama T. Dietary supplementation of gamma-linolenic acid improves skin parameters in subjects with dry skin and mild atopic dermatitis. J Oleo Sci. 2011;60:597-607.

3. James MJ, Ursin VM, Cleland LG. Metabolism of stearidonic acid in human subjects: comparison with the metabolism of other $n-3$ fatty acids. Am J Clin Nutr. 2003:77:1140-5.

4. Harris WS. Stearidonic acid-enhanced soybean oil: a plant-based source of (n-3) fatty acids for foods. J Nutr. 2012:142:600S-4S. https://doi.org/10.3945/in.111.146613.

5. Guil-Guerrero JL. Stearidonic acid (18:4n-3): metabolism, nutritional importance, medical uses and natural sources. Eur J Lipid Sci Technol. 2007. 109:1226-36. https://doi.org/10.1002/ejlt.200700207.

6. Hudson BJF. Evening primrose (Oenothera spp.) oil and seed. J Am Oil Chem Soc. 1984;61:540-3. https://doi.org/10.1007/bf02677026.

7. Traitler $\mathrm{H}$, Winter $\mathrm{H}$, Richli $\mathrm{U}$, Ingenbleek $\mathrm{Y}$. Characterization of gammalinolenic acid in Ribes seed. Lipids. 1984;19:923-8.

8. Aitzetmuller K, Werner G. Stearidonic Acid (18-4-Omega-3) in Primula-Florindae. Phytochemistry. 1991;30:4011-3. https://doi.org/10.1016/0031-9422(91)83454-S.

9. Guil-Guerrero JL, Gomez-Mercado F, Garcia-Maroto F, Campra-Madrid P. Occurrence and characterization of oils rich in gamma-linolenic acid part I: Echium seeds from Macaronesia. Phytochemistry. 2000;53:451-6.

10. Callaway JC, Tennil T, Pate DW. Occurrence of "omega-3" steardonic acid (cis-6,9,12,15-octadecatetraenoic acid) in hemp (Cannabis sativa L.) seed. J Int Hemp Assoc. 1996;3:61-3.

11. Guil-Guerrero JL, Garcia-Maroto F, Vilches-Ferron MA, Lopez-Alonso D. Gamma-linolenic acid from fourteen boraginaceae species. Ind Crop Prod. 2003;18:85-9. https://doi.org/10.1016/S0926-6690(03)00036-0.

12. Liu JW, Demichele S, Bergana M, Bobik E, Hastilow C, Chuang LT, Mukerji P, Huang YS. Characterization of oil exhibiting high gamma-linolenic acid from a genetically transformed canola strain. J Am Oil Chem Soc. 2001;78:489-93. https://doi.org/10.1007/s11746-001-0291-2.

13. Hong H, Datla N, Reed DW, Covello PS, Mackenzie SL, Qiu X. High-level production of gamma-linolenic acid in Brassica juncea using a Delta 6 desaturase from Pythium irregulare. Plant Physiol. 2002;129:354-62. https://doi.org/10.1104/pp.001495.
14. Sayanova O, Haslam R, Venegas-Caleron M, Napier JA. Identification of Primula "front-end" desaturases with distinct n-6 or n-3 substrate preferences. Planta. 2006;224:1269-77. https://doi.org/10.1007/s00425-006-0306-0.

15. Ruiz-Lopez N, Haslam RP, Venegas-Caleron M, Larson TR, Graham IA, Napier JA, Sayanova O. The synthesis and accumulation of stearidonic acid in transgenic plants: a novel source of 'heart-healthy' omega-3 fatty acids. Plant Biotechnol J. 2009;7:704-16. https://doi.org/10.1111/j.1467-7652.2009.00436.x.

16. Reddy AS, Nuccio ML, Gross LM, Thomas TL. Isolation of a Delta-6desaturase gene from the cyanobacterium Synechocystis Sp strain Pcc-6803 by gain-of-function expression in Anabaena Sp strain Pcc-7120. Plant Mol Biol. 1993;22:293-300. https://doi.org/10.1007/Bf00014936.

17. Sperling $P$, Zahringer $U$, Heinz E. A sphingolipid desaturase from higher plants. Identification of a new cytochrome b5 fusion protein. J Biol Chem. 1998;273:28590-6

18. Singh SP, Zhou XR, Liu Q, Stymne S, Green AG. Metabolic engineering of new fatty acids in plants. Curr Opin Plant Biol. 2005:8:197-203. https://doi.org/10.1016/j.pbi.2005.01.012.

19. Napier JA, Sayanova O, Stobart AK, Shewry PR. A new class of cytochrome b5 fusion proteins. Biochem J. 1997:328:717-8.

20. Sayanova O, Smith MA, Lapinskas P, Stobart AK, Dobson G, Christie WW, Shewry PR, Napier JA. Expression of a borage desaturase cDNA containing an N-terminal cytochrome b5 domain results in the accumulation of high levels of delta6-desaturated fatty acids in transgenic tobacco. Proc Natl Acad Sci U S A. 1997:94:4211-6.

21. Shanklin J, Cahoon EB. Desaturation and related modifications of fatty acids. Annu Rev Plant Physiol Plant Mol Biol. 1998;49:611-41. https://doi.org/10. 1146/annurev.arplant.49.1.611.

22. Asif M. Health effects of omega-3,6,9 fatty acids: Perilla frutescens is a good example of plant oils. Orient Pharm Exp Med. 2011;11:51-9. https://doi.org/ 10.1007/s13596-011-0002-x

23. Kim HU, Lee K-R, Shim D, Lee JH, Chen GQ, Hwang S. Transcriptome analysis and identification of genes associated with $\omega-3$ fatty acid biosynthesis in Perilla frutescens (L.) var. frutescens. BMC Genomics. 2016;17 474. https://doi.org/10.1186/s12864-016-2805-0.

24. Shin HS, Kim SW. Lipid composition of Perilla seed. J Am Oil Chem Soc. 1994;71:619-22. https://doi.org/10.1007/Bf02540589.

25. Murashige T, Skoog F. A revised medium for rapid growth and bioassays with tobacco tissue cultures. Physiol Plant. 1962:15:473-97.

26. Kim KH, Lee YH, Kim D, Park YH, Lee JY, Hwang YS, Kim YH. Agrobacteriummediated genetic transformation of Perilla frutescens. Plant Cell Rep. 2004; 23:386-90. https://doi.org/10.1007/s00299-004-0825-8.

27. Kim SH, Kim JB, Kim SY, Roh KH, Kim HU, Lee KR, Jang YS, Kwon M, Park JS, Functional characterization of a delta 6-desaturase gene from the black seabream (Acanthopagrus schlegeli). Biotechnol Lett. 2011;33:1185-93. https://doi.org/10.1007/s10529-011-0555-2.

28. Kim HU, Lee KR, Go YS, Jung JH, Suh MC, Kim JB. Endoplasmic reticulumlocated PDAT1-2 from castor bean enhances hydroxy fatty acid accumulation in transgenic plants. Plant Cell Physiol. 2011;52:983-93. https://doi.org/10.1093/pcp/pcr051.

29. Los DA, Murata N. Structure and expression of fatty acid desaturases. Biochim Biophys Acta. 1998:1394:3-15.

30. Sayanova O, Beaudoin F, Libisch B, Castel A, Shewry PR, Napier JA. Mutagenesis and heterologous expression in yeast of a plant Delta(6)-fatty acid desaturase. J Exp Bot. 2001;52:1581-5. https://doi.org/10.1093/jexbot/52.360.1581.

31. Okuley J, Lightner J, Feldmann K, Yadav N, Lark E, Browse J. Arabidopsis FAD2 gene encodes the enzyme that is essential for polyunsaturated lipid synthesis. Plant Cell. 1994;6:147-58. https://doi.org/10.1105/tpc.6.1.147.

32. Lim JM, Vikramathithan J, Hwangbo K, Ahn JW, Park Yl, Choi DW, Jeong WJ. Threonine 286 of fatty acid desaturase 7 is essential for omega-3 fatty acid desaturation in the green microalga Chlamydomonas reinhardtii. Front Microbiol. 2015;6:66. https://doi.org/10.3389/fmicb.2015.00066.

33. Lee $K R$, Lee $Y$, Kim EH, Lee $S B$, Roh KH, Kim JB, Kang HC, Kim HU. Functional identification of oleate 12-desaturase and omega-3 fatty acid desaturase genes from Perilla frutescens var. frutescens. Plant Cell Rep. 2016:35:252337. https://doi.org/10.1007/s00299-016-2053-4

34. Higgins TJ, Newbigin EJ, Spencer D, Llewellyn DJ, Craig S. The sequence of a pea vicilin gene and its expression in transgenic tobacco plants. Plant $\mathrm{Mol}$ Biol. 1988;11:683-95. https://doi.org/10.1007/BF00017468.

35. Bossie MA, Martin CE. Nutritional regulation of yeast Delta-9 fatty-acid desaturase activity. J Bacteriol. 1989:171:6409-13. https://doi.org/10. 1128/jb.171.12.6409-13.1989. 
36. Furtado A, Henry R, Takaiwa F. Comparison of promoters in transgenic rice. Plant Biotechnol J. 2008;66679-93. https://doi.org/10.1111/j.1467-7652.2008.00352x.

37. Gao JP, Ajjawi I, Manoli A, Sawin A, Xu C, Froehlich JE, Last RL, Benning C. FATTY ACID DESATURASE4 of Arabidopsis encodes a protein distinct from characterized fatty acid desaturases. Plant J. 2009;60:832-9. https://doi.org/ 10.1111/j.1365-313X.2009.04001.X.

38. Devor KA, Mudd JB. Structural analysis of phosphatidylcholine of plant tissue. J Lipid Res. 1971;12:396-402.

39. Simopoulos AP. The importance of the ratio of omega-6/omega-3 essential fatty acids. Biomed Pharmacother. 2002;56:365-79. https://doi.org/10.1016/ S0753-3322(02)00253-6.

40. Goffman FD, Galletti S. Gamma-linolenic acid and tocopherol contents in the seed oil of 47 accessions from several Ribes species. J Agric Food Chem. 2001;49:349-54. https://doi.org/10.1021/jf0006729.

41. Clough P. Sources and production of specialty oils containing GLA and stearidonic acid. Lipid Technol. 1993;5:9-12.

42. Abedi E, Sahari MA. Long-chain polyunsaturated fatty acid sources and evaluation of their nutritional and functional properties. Food Sci Nutr. 2014 2(5):443-63. https://doi.org/10.1002/fsn3.121.

43. Coupland K. Stearidonic acid: a plant produced omega-3 PUFA and a potential alternative for marine oil fatty acids. Lipid Technol. 2008;20:152-4. https://doi.org/10.1002/lite.200800045.

44. Reddy AS, Thomas TL. Expression of a cyanobacterial delta 6-desaturase gene results in gamma-linolenic acid production in transgenic plants. Nat Biotechnol. 1996;14:639-42. https://doi.org/10.1038/nbt0596-639.

45. Eckert H, La Vallee B, Schweiger BJ, Kinney AJ, Cahoon EB, Clemente T. Co-expression of the borage Delta 6 desaturase and the Arabidopsis Delta 15 desaturase results in high accumulation of stearidonic acid in the seeds of transgenic soybean. Planta. 2006; 224:1050-7. https:/doi.org/10.1007/s00425-006-0291-3.

46. Nykiforuk CL, Shewmaker C, Harry I, Yurchenko OP, Zhang M, Reed C, Oinam GS, Zaplachinski S, Fidantsef A, Boothe JG, Moloney MM. High level accumulation of gamma linolenic acid (C18:3Delta6.9,12 cis) in transgenic safflower (Carthamus tinctorius) seeds. Transgenic Res. 2012;21:367-81. https://doi.org/10.1007/s11248-011-9543-5.

47. Sayanova OV, Beaudoin F, Michaelson LV, Shewry PR, Napier JA. Identification of primula fatty acid delta 6-desaturases with $\mathrm{n}$-3 substrate preferences. FEBS Lett. 2003;542:100-4.

Ready to submit your research? Choose BMC and benefit from:

- fast, convenient online submission

- thorough peer review by experienced researchers in your field

- rapid publication on acceptance

- support for research data, including large and complex data types

- gold Open Access which fosters wider collaboration and increased citations

- maximum visibility for your research: over $100 \mathrm{M}$ website views per year

At $\mathrm{BMC}$, research is always in progress.

Learn more biomedcentral.com/submissions 